\title{
Revenue and yield management: a perspective article
}

\author{
Giampaolo Viglia ${ }^{\mathrm{a}}$, Graziano Abrate ${ }^{\mathrm{b}}$,
}

\begin{abstract}
This paper discusses the evolution of revues and yield managing. The study explains briefly the history and predicts the future of revenue management, offering a visual model to identify the main challenges faced by revenue managers.

Four emerging issues will affect four notable themes for a fertile RM application, namely: i) organizational culture ii) dynamic pricing, both in terms of intertemporal price discrimination and inventory controls, iii) personalized pricing and iv) distribution channels.

When predicting the future of hotel revenue management, technological and communication abilities are central for the next decade of revenue management. developments break the boundaries between revenue management, sales and distribution, removing organizational barriers toward organisational intelligence.
\end{abstract}

Keywords: revenue management, organizational culture, dynamic pricing, personalised pricing, distribution channels, yield

${ }^{a}$ University of Portsmouth, Department of Marketing and Sales, Portland Street, PO13DE, United Kingdom. Tel: +44 0239284 4148. Email:

giampaolo.viglia@port.ac.uk; corresponding author.

b University of Piemonte Orientale "A. Avogadro", Department of Economics and Business, Via Perrone 18, 28100 Novara, Italy. Tel: +39 0321 375440. Fax: +39 0321

375405. Email: graziano.abrate@uniupo.it 


\section{Revenue and yield management: a perspective article}

\section{Introduction}

Whist yield management primarily focused on inventory controls, revenue management emerged as a more agile and real time method that takes into consideration all profit centres holistically. This study explains briefly the history and predicts the future of revenue management, offering a visual model to identify the main challenges faced by revenue managers.

Past perspective 75 years of developments 1946-2020

Early models of revenue management go back to the so-called Littlewood's rule (Littlewood, 1972) and to the concept of expected marginal seat revenue (Balobaba, 1987). American Airlines developed the world's first yield management system in 1985 . This innovative approach progressed integration of forecasting, optimization and reservation systems (Yeoman, 2016). Most of the research came from operation and finance (Harris and Brown, 1998; Kimes and Wirtz, 2015). Staff involved in revenue management had generally a very technical background and focused on forecasting or other operations models across airlines, restaurants and hotels (Jones and Lockwood, 1998).

Future perspective 75 years 2020-2095

Revenue management is increasingly marketing-led, with tailored practices such as personalized pricing or personalized rooms (Tu et al., 2017). The integration between operations and marketing - as well as between strategy and tactics - is key for successful revenue management. Hotels adopt key performance indicators that go beyond room revenues, such as REVPar (Revenue per available room), which accounts for all outlets in the property, or GopPar (gross operating profit per available room), which accounts for expenses and cross selling (Ferguson and Smith, 2014). Ivanov and Zhechev (2012) provide a detailed overview of the specific revenue centres, including room division, $\mathrm{F} \& \mathrm{~B}$, function rooms, spa \& fitness facilities, etc.

This tendency towards a more holistic approach to performance can include quality and reputation management, as well as sustainability elements. Revenue managers face the challenge of how to integrate new technological advances, using big data analytics, artificial intelligence and related tools extensively (Choi et al., 2018). Capturing, analyzing and interpreting the right data in real time (Buhalis and Sinarta, 2019) using artificial intelligence and robots will be critical (Buhalis et al. 2019). Four emerging issues will affect four notable themes for a fertile RM application, namely: i) organizational culture ii) dynamic pricing, both in terms of intertemporal price discrimination and inventory controls, iii) personalized pricing and iv) distribution channels. Figure 1 summarizes the different forward-looking strands. 
Figure 1. The future of revenue management

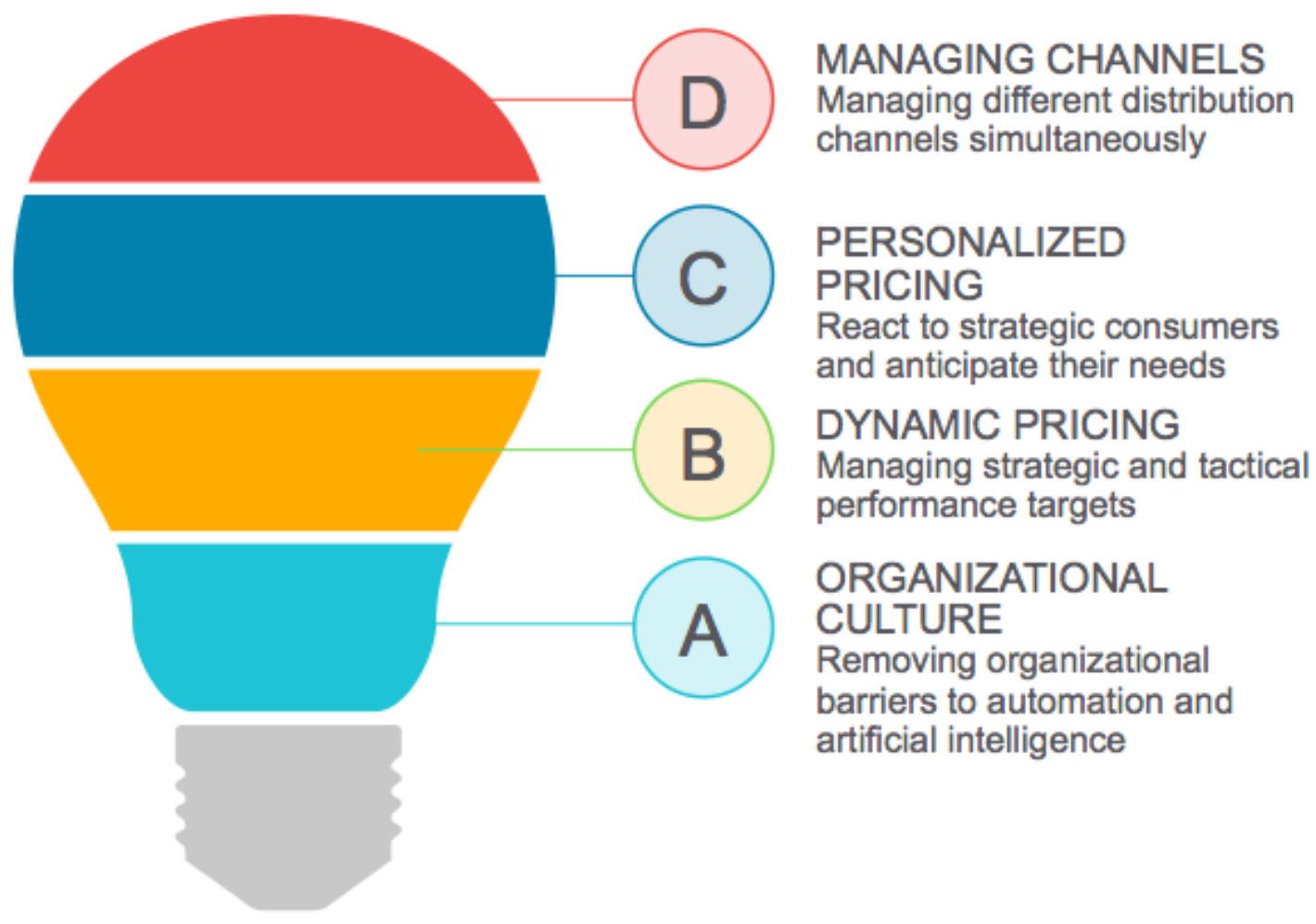

Revenue management is complex and requires quite advanced skills (Wang et al., 2015), and a dynamic organizational structure (Aubke et al., 2014). The use of big data poses lingering questions on data privacy and threats to human and social welfare. Automation and robotics bring internal resistance to the adoption of the latest available technologies. Organization support is crucial to keep a collaborative workplace climate (Li et al., 2019). In this sense, training for managers and appropriate IT infrastructure for a streamlined revenue management are essential elements (Selmi and Dornier (2011).

Dynamic pricing occur for two different reasons, intertemporal price discrimination or inventory controls. In the first case, the company actively proposes real time price adjustments due to different competing conditions or to the idea of segmenting different groups of customers based on their urgency and flexibility. In the second case, the company has already divided capacity into chunks a priory and has assigned a price tag to each chunk (Melis and Piga, 2017). Whichever way it goes, the consumer is exposed to dynamic price variations. Recent research shows that an intense use of dynamic pricing is beneficial for revenue maximization, outweighing the potential risk due to price fairness concerns (Abrate et al., 2019). The integration of tactical revenue management tools with more strategic reputation management objectives provides a further direction for future research. 
Personalized pricing and mass customization will transform each individual to a market segment of one. Behavior-based price discrimination implies charging a personalized price to each customer, according to their past purchase history, location, and other finegrained data (Caillaud and De Nijs, 2014). Technological tools have made easier for companies to apply personalized pricing. The term has also been recently used when looking at price fairness implications (Richards et al., 2016) or at consumers' strategic reaction (Aviv and Pazgal, 2008). Personalized pricing is clearly one of the key elements in the future of revenue management, as the accurate knowledge of the individual customer, paired with the use of artificial intelligence will offer real-time price sensitivity considerations. Automated revenue management tools will anticipate customer needs: artificial intelligence will make preliminary bookings that will be just finally approved by the consumer.

Distribution channels determine revenue and profitability for tourism and hospitality principles (Martin-Fuentes and Mellinas, 2018). When looking at consumer purchases, online travel agencies (OTAs) have become the most popular distribution channel for hotel rooms, with nearly $70 \%$ of rooms sold (Lee, Guillet and Law, 2013; Verhoef, Kannan and Inman, 2015). Multi-channel approaches are worthwhile to capture different segments. Yang and Leung (2018), comparing TripAdvisor to HotelTonight, found that offering a complimentary access to services had a differential impact across channels. Engaging stakeholders through complimentary platforms seems to be a clear promising avenue going forward (Viglia et al., 2018). With an increasing share of strategic consumers using comparison online tools, integration between platforms and an omnichannel strategy are essential (Gallino et al. 2017).

\section{Conclusions}

Four key topics will shape the future of revenue management, namely: organizational culture, dynamic pricing, personalized pricing and managing channels. When predicting the future of hotel revenue management, Kimes (2011) argued that technological and communication abilities are central for the next decade of revenue management. Technological developments break the boundaries between revenue management, sales and distribution, removing organizational barriers toward organisational intelligence.

\section{References}

Abrate, G., Nicolau, J. L., and Viglia, G. (2019), "The impact of dynamic price variability on revenue maximization", Tourism Management, Vol. 74, pp. 224-233.

Aubke, F., Woeber, K., Scott, N., and Baggio, R. (2014), "Knowledge sharing in revenue management teams: Antecedents and consequences of group cohesion", International Journal of Hospitality Management, Vol. 41, pp. 149-157. 
Aviv, Y., and Pazgal, A. (2008), "Optimal pricing of seasonal products in the presence of forward-looking consumers", Manufacturing \& Service Operations Management, Vol. 10 No. 3, pp. 339-359.

Belobaba, P. P. (1987), "Survey Paper-Airline yield management an overview of seat inventory control”, Transportation science, Vol. 21 No. 2, pp. 63-73.

Buhalis, D., Harwood, T., Bogicevic, V., Viglia, G., Beldona, S., and Hofacker, C. (2019), "Technological disruptions in Services: lessons from Tourism and Hospitality", Journal of Service Management, https://dx.doi.org/10.1108/JOSM-12-2018-0398

Buhalis, D., and Sinarta, Y. (2019), "Real-time co-creation and nowness service: lessons from tourism and hospitality", Journal of Travel and Tourism Marketing, Vol. 36 No. 5, pp.563-582.

Caillaud, B., and De Nijs, R. (2014), "Strategic loyalty reward in dynamic price discrimination”, Marketing Science, Vol. 33 No. 5, pp. 725-742.

Choi, T. M., Wallace, S. W., and Wang, Y. (2018), "Big data analytics in operations management", Production and Operations Management, Vol. 27 No. 10, pp. 1868-1883.

Ferguson, M., and Smith, S. (2014), "The changing landscape of hotel revenue management and the role of the hotel revenue manager", Journal of Revenue and Pricing Management, Vol. 13 No. 3, pp. 224-232.

Gallino S., Moreno A., and Stamatopoulis I. (2017), "Channel integration, sales dispersion, and inventory management", Management Science, Vol. 63, pp. 2813-2831.

Harris, P. J., and Brown, J. B. (1998), "Research and development in hospitality accounting and financial management", International Journal of Hospitality Management, Vol. 17 No. 2, pp. 161-182.

Ivanov, S., and Zhechev, V. (2012), "Hotel revenue management-a critical literature review”, Turizam: međunarodni znanstveno-stručni časopis, Vol. 60 No. 2, pp. 175-197.

Jones, P., and Lockwood, A. (1998), "Operations management research in the hospitality industry”, International Journal of Hospitality Management, Vol. 17 No. 2, pp. 183-202.

Kimes, S. E. (2011), "The future of hotel revenue management", Journal of Revenue and Pricing Management, Vol. 10 No. 1, pp. 62-72.

Kimes, S. E., and Wirtz, J. (2015), "Revenue management: Advanced strategies and tools to enhance firm profitability", Foundations and Trends® in Marketing, Vol. 8 No. 1, pp. $1-68$. 
Lee, H. A., Denizci Guillet, B., and Law, R. (2013), "An examination of the relationship between online travel agents and hotels: A case study of Choice Hotels International and Expedia.com”, Cornell Hospitality Quarterly, Vol. 54 No. 1, pp. 95-107.

Li, J. J., Bonn, M. A., and Ye, B. H. (2019), "Hotel employee's artificial intelligence and robotics awareness and its impact on turnover intention: The moderating roles of perceived organizational support and competitive psychological climate", Tourism Management, Vol. 73, pp. 172-181.

Littlewood, K. (1972), "Forecasting and Control of Passenger Bookings", in AGIFORS Symposium Proceedings, Nathanya, Israel, Vol. 12, pp. 95-117, reprinted in Journal of Revenue and Pricing Management, Vol. 4 No. 2, pp. 111-123.

Martin-Fuentes, E. and Mellinas, J., (2018), "Hotels that most rely on Booking.com online travel agencies (OTAs) and hotel distribution channels", Tourism Review, Vol. 73 No. 4, pp. 465-479.

Melis, G., and Piga, C. A. (2017), “Are all online hotel prices created dynamic? An empirical assessment”, International Journal of Hospitality Management, Vol. 67, pp. 163-173.

Richards, T. J., Liaukonyte, J., and Streletskaya, N. A. (2016), "Personalized pricing and price fairness", International Journal of Industrial Organization, Vol. 44, pp. 138-153.

Selmi, N., and Dornier, R. (2011), "Yield management in the French hotel business: An assessment of the importance of the human factor", International Business Research, Vol. 4 No. 2, pp. 58-66.

Tu, Y., Neuhofer, B., and Viglia, G. (2018), "When co-creation pays: stimulating engagement to increase revenues", International Journal of Contemporary Hospitality Management, Vol. 30 No. 4, pp. 2093-2111.

Verhoef, P. C., Kannan, P. K., and Inman, J. J. (2015), "From multi-channel retailing to omni-channel retailing: introduction to the special issue on multi-channel retailing", Journal of retailing, Vol. 91 No. 2, pp. 174-181.

Viglia, G., Pera, R., and Bigné, E. (2018), “The determinants of stakeholder engagement in digital platforms", Journal of Business Research, Vol. 89, pp. 404-410.

Wang, X. L., Yoonjoung Heo, C., Schwartz, Z., Legohérel, P., and Specklin, F. (2015), "Revenue management: Progress, challenges, and research prospects", Journal of Travel \& Tourism Marketing, Vol. 32 No. 7, pp. 797-811.

Yang, Y., and Leung, X. Y. (2018), "A better last-minute hotel deal via app? Crosschannel price disparities between HotelTonight and OTAs", Tourism Management, Vol. 68, pp. 198-209. 
Yeoman, I. (2016), "The history of revenue and pricing management -15 years and more", Journal of Revenue and Pricing Management, Vol. 15 No. 3-4, pp. 185-196. 